\title{
Integrated Fruit Growing in Europe
}

\author{
S. Sansavini \\ Istituto Coltivazioni Arboree, University di Bologna, 40126 Bologna, Italy
}

Integrated agriculture, a new force in Europe, is derived from the expansion of the principles of integrated pest management (IPM) to all field practices. Unlike organic farming, integrated agriculture does not seek the elimination of chemicals, but rather strives to reduce high-environmental impact methods and to encourage high technology with a low environmental impact. Integrated fruit growing has special relevance to Europe, where much of the production is concentrated in intensive family farm operations. The successful implementation of integrated fruit growing will involve close coordination of national and regional governments, university research, extension services, growers, and grower organizations.

\section{Intensive management of orchards and vineyards: An irreversible trend}

European fruit growing has taken the path towards specialization and intensificationthe only means capable of increasing the viability of the small-scale operations that account for most of Europe's production. In contrast, large holdings, which have the apparent advantages of scale, including the capability to mechanize, are having enormous problems due to high labor costs, a direct consequence of national policies.

Crop intensification seeks four broad objectives: 1) Emphasize crop quality rather than yield increase (which, beyond a certain limit, is incompatible with quality). 2) Shorten cropping life cycles to amortize costs more rapidly. 3) Simplify cropping patterns, despite the risks of over-specialization of monospecies and even monocultivar orchards. 4) Cut production costs by reducing tree size to facilitate management from the ground and mechanize most operations except pruning and harvesting,' which can be mechanically as sisted.

The annual labor input per hectare for orchard crops is at least tenfold greater than for forage, cereal, or industrial crops (100

Received for publication 25 Sept. 1989. The assistance of Jules Janick in editing this manuscript is gratefully acknowledged. vs. 10 working days). To this must be added the large capital outlays per hectare required for orchard establishment (US\$10 to $\$ 15$ thousand) and at least US\$7 to $\$ 12$ thousand yearly overhead. Fruit growing is a high-risk business that demands professional expertise, proven entrepreneurship, and the marketing power provided by grower associations to be successful and competitive in the marketplace. The removal of international trade barriers and the rising imports in Europe of fresh fruit from Mediterranean and southernhemisphere countries are exposing Europe's fruit industry to overly aggressive competition for markets and the build-up of surpluses -that are adversely affecting growers' income, as well as aggravating fiscal policies of the European Economic Community (EEC).

Increasing competition has been the rationale to justify the increased research and development of crop protection management and storage techniques designed to safeguard harvests and extend marketing over time. Many of these management practices have relied on chemical techniques (pesticides, growth regulators, fertilizers) that have alarmed environmentalists, and, more recently, the general public.

\section{Integrated or organic farming}

The dilemma facing individual fruit growers in light of environmental concerns is the need both to remain economically viable and to reduce certain production inputs, such as pesticides and growth regulators. This development has led to a new strategy called "Integrated Agriculture" This strategy is designed to take into greater account the biological aspects of crop management techniques. Unlike organic agriculture, however, it is linked to the realization by growers that the margin for error is very small, for their task remains that of economic production for an increasingly selective and competitive market.

Integrated management has been a proven success in the fruit industries of Switzerland (where this new approach was first formulated 8 to 10 years ago), France, Germany, and the Netherlands. However, the realistic and non-mystifying concept of integrated management in fruit and other crops is today being countered by the call for an organic agriculture. Although motivated by humanitarian and idealistic concerns worthy of consideration, organic agriculture has no chance of establishing itself on any practical scale as a replacement for the integrated approach. The reasons are several and fundamental. First, the complete elimination of pesticides or chemical fertilizers would mean the economic collapse of farms engaged in intensive crop operation. Second, shifting the increased cost associated with organic agriculture to society at large (by allotting subsidies to compensate for farm conversion and crop losses) or to the consumer (by provoking uncontrolled price rises for "organic produce") would impoverish agriculture, while, at the same time, increasing the share of governmental revenue through subsidies for organic farming without returning any real benefits over what can be achieved by an integrated system. Third, the organic techniques (i.e., the rejection of currently available chemicals) may be applicable on a limited scale in special situations, but would inevitably diminish the vast crop yields required for an expanding world population. If the new advances of biotechnology, with the attendant risks, are not employed, organic farming will amount to neo-Ludditism: a reversion to the prohibition of scientific and technological advances. Fourth and last, it would entail the implementation of a crop control system (incurring even more costs) to guarantee "organic purity" to the consumer as well as requiring a series of advertising campaigns to favor an elite segment of the produce market to the detriment of the mass market.

\section{Organic farming in practice}

Much has already been said and written on the subject of organic farming. The term itself, however, is misleading because conventional farming is nothing but an organic process that is technically developed and guided by ongoing scientific advances.

Proponents of organic farming are seeking, above all, to break with conventional 
agriculture. They are searching for an alternative agriculture that will employ new methods, new crop strategies, and even new species. A perusal of bibliographical sources reveals there is little help to be gleaned from an historical analysis of organic farming methods. The list includes Rudolf Steiner's "biodynamics" farming, Howard-Balfour's organic gardening methods involving composts, the rather bizarre and pseudoscientific concept formulated in the 1960 s by Lemaire-Boucher-Kervran (see their theory of the biological transmutation of mineral elements), the philosophically based "macrobiotic" farming that originated in Germany $\approx 70$ years ago, and "biorganic" farming propounded by the bacteriologist Nissle and perfected by H.P. Rusch and H. Muller in Switzerland, Other systems, while admitting the use of chemicals, encourage organic, "green manures", as in the organic orchards promoted by the ANOG Association in Germany in 1962 or the natural Japanese method proposed by M. Fukuoka that emphasizes crop rotation and physical soil management. practices in contrast to chemicals.

Italy. None of the organic methods referred to above are specifically cited in legislative proposals recently drafted by the Italian parliament and designed to eliminate residues of pesticides and other contaminants such as nitrates; to safeguard the environment; to protect the soil from the various forms of exhaustion, impoverishment, or erosion; to reduce yields (so as to prevent surpluses); and to revert to aless technologically dependent agricultural system. These draft bills, however, do admit to high technology biological products (e.g., the use of Bacillus thuringiensis) and a strictly limited employment of chemicals and fertilizers. The rationale behind them is the assumption, not scientifically demonstrated, that organic produce is of better quality in terms of nutritional elements, digestion, purity, and health in general.

And what-of the economic aspect of organic agriculture? It is confidently assumed that the higher prices that organic produce bring in the marketplace will offset its higher costs and lower yields. But one also gets the impression that substantial government subsidies are in the offing to "reward" growers for the beneficent social role they would play by opting for organic techniques. Thus far, the only legislative measure enacted in Italy (by the Lazio Region) makes provision for a payment of $70 \%$ ( $80 \%$ for cooperatives) to those "organic farms that have been enrolled for at least three years"! (The total allocation amounts to about US\$1 million.) Two to 7 years are provided for the conversion from conventional to organic farm operations, with the produce to be marketed under the logo "organic produce" (or "organic processing" for industry). The farms themselves will be subject to twice-yearly spot checks and delivery monitoring (to verify that bills of lading are correct) by the local boards of health. All synthetic chemicals, hormonal products, and fertilizers are banned, except those that are organic and biodegradable.

Unfortunately, there are no convincing experimental data to support the validity of the systems proposed. In Italy, there are $\approx 1000$ farms engaged in organic cultivation, with production slated either for self-consumption or to supply small market sectors (such as regular customers). A recent survey reports that there is a rising demand for organic products and that part of the consumer public is willing to pay higher prices for them ( $10 \%$ to $40 \%$ more), but the extent of this market is unknown.

Federal Republic of Germany. There are some research data from Germany, where biodynamics farming has been practiced for several decades and has a small, but local, following ( $<1 \%$ of the population). Biodynamics farming is linked to system's that promote the use of organic matter and have recourse to unusual techniques, such as the use of extract of nettles and equisetums and the observance of certain rituals. Excellent results have been reported by Newrzella (see Reinken, 1988) for compost based on wheat and barley straw, to which is added liquid swine manure and several other substances. Such a method, if applied in Italy, where there are intensive swine breeding operations, could help reduce the problems of effluents that pollute the water table.

At Darmstadt, a research group is working on alternative biodynamics farming in collaboration with $\mathrm{H}$. Muller in Bern. Trials conducted from 1978 to 1985 , in which $180 \mathrm{t} \cdot \mathrm{ha}^{1}{ }^{1}$ of compost were used in an apple orchard and $250 \mathrm{t} \cdot \mathrm{ha}^{-1}$ for other horticultural crops, showed an increase in $\mathrm{pH}$, calcium, organic matter, and mycorrhizae (Reinken, 1988). Insecticide treatments in the same trials were reduced almost to nil in the orchard (Forficula was used against aphids), while fungicide treatments were increased from two to eight for the vegetable crops and from 10 to 12 for the orchard crops.

Yields dropped an average of $19 \%$ in the vegetable crops (cabbage, lettuce, spinach, carrot, bean) and $37 \%$ in apple ('Cox's' 'Orange Pippin', 'Belle de Boskoop', 'Roter Berlepsch'), a fact partly ascribable to excessive plant vigor (due to compost) that favored certain insects (such as Capua spp.). Most noteworthy was the drastic quality loss of both vegetable crops and apples (increased cracking) in the biodynamics plots. Residue tests on fruits showed that values in the conventional plots were within safety limits; i.e., not more than one-fifth of the level permitted by law, while fruit from biodynamics plots had only traces (mainly sulfur).

In their study of fruit and vegetable quality, Wedler and Overbeck (1987) reported no significant differences between organic and conventional produce in dry matter, total nitrogen, proteins, nitrate, calcium, sodium, phosphorous, sugars, acids, polysaccharides, vitamin $\mathrm{C}$, appearance, and taste. Higher levels of nitrates, chlorine, and acids were detected in organically grown plants within a few years, but there was no evidence that the nitrates were carcinogenic.
Finally, the German study considered economic aspects, demonstrating that compost fertilization in the biodynamics plots cost 2 to 8 times more than chemical fertilizer and labor averaged $76 \%$ more for vegetable crops and $10 \%$ to $20 \%$ greater for apple. Despite this, the $10 \%$ price rise from biodynamics produce was enough to raise return on investments by almost US\$700/ha, while the gross return per hectare for biodynamics fruit crops was double that of the conventional.

Conclusions reached by the German researchers indicate that much experimental work still needs to be done before the validity of biodynamics agriculture can be demonstrated, especially in regard to the specific chemical agents allowed (Steiner, 1979; Tegethof, 1987; as cited in Reinken, 1988; Goldhammer, as cited in Van Tiemann, 1989). Tests need to include-techniques such as enhancing plant resistance by means of natural substances such as algae extracts.

Yugoslavia. The PKB-Agroekonomik Institute has begun a program of production, processing,- and marketing of "Power of Nature" products. They have a quality distinction label if they meet certain standards, as well as having $50 \%$ less pesticide and other contaminant residues than allowed under Yugoslav law. They can also bear a so-called "gold label" if organically grown; i.e., cultivated without chemicals and fertilizers and at least $30 \mathrm{~km}$ from urban centers or industrial plants and $10 \mathrm{~km}$ from main thoroughfares. For those items of produce bearing only the quality distinction label (silver label) the distances alone are lowered to 10 and $5 \mathrm{~km}$, respectively.

\section{Integrated farming}

"Integrated farming" is the innovation of European agriculture in the 1980s. The concept of integrated farming is linked to a certain extent to organic farming. The definition stems from integrated pest management (IPM) that was first employed in fruit growing, amid general skepticism, by Steiner in 1953 at Stuttgart. Today the term IPM infers a "combination of strategies, including biological, biotechnical, genetic and field management methods, designed to reduce to a minimum the use of pesticides and chemical agents". Integrated farming, a natural offshoot of IPM, gained currency in the 1970s as an alternative model to conventional agriculture and in Germany today it is part and parcel of the new, intensive fruit industry (Van Tiemann, 1989).

Another forerunner of integrated farming dates to 1980 in Switzerland and was put forth by M. Baggiolini, who compiled detailed studies of the population dynamics of several fruit pests at the Changins Station. The concept is called "integrated cropping/ production" and was promoted by the International Organization of Biological Control (OILB), founded in 1965. It incorporates not only IPM, but all field management techniques designed to produce crops that meet both commercial and consumer demands while safeguarding the environment. 
Since 1982, a European working group, composed mainly of physiologists from seven countries, has been promoting and conducting "integrated production" research so as to safeguard the economic interests of growers and the health and nutritional expectations of consumers. Since its 1987 meeting at Wädenswill, Switzerland, the group has also begun to coordinate research lines with a view to obtaining the support of the EEC.

Europe's farmers have not remained aloof from these issues. Two associations of fruit and grape growers have been founded in Switzerland: GALTI (Groupement des Arboriculteurs Lémaniques Pratiquant les Techniques Integrées) formed in 1976, with its own by-laws and trademark, and CULTIVAL (120 members) formed in 1986. Both associations propose to offer consumers greater guarantees in exchange for better market prices-aims that are analogous to those pursued in Switzerland by the Migros chain (Marcelle, 1988), or in the Netherlands, where in 1987 appeals by the NFO (Natural Fruit Organization) in favor of the new IMP techniques led to a $10 \%$ drop in the use of chemicals in fruit growing. The myth in France of absolute crop protection prevailing in the 1960s has given way to the current awareness of biological realities. The initial failures of chemicals to control aphids (because of resistance to organic phosphorus compounds) and subsequent-unsuccessful attempts against Psylla and several mites (due to resistance against systemic and specific action chemicals) induced researchers to consider other approaches.

In addition to these pests, other problems arose, such as the appearance and spread of viruses and mycoplasms, soil problems (root waterlogging), physiological disorders, diseases from the lack or excess of nutrients, and cropping irregularities, such as alternate bearing. It was only natural, then, for IPM to be extended to the control and management of the entire production process-hence, integrated farming.

France, through a "National Committee for the Promotion of Integrated Fruit Production", has been very active in Europe, thanks also to an aggressive fruit marketing strategy undertaken directly by growers' associations (SOPEXA). Other initiatives on behalf of integrated fruit growing have sprung up in both Germanys. In the Hamburg area, for example, a growers' group has adopted a production code - a moral commitment to comply with the management techniques freely underwritten by its member. In Spain, on the other hand, the issue is still quite marginal.

Italy presents a much more heterogeneous picture due to regional differences. The initiatives undertaken in the Trentino and Alto Adige Regions have been highly successful, where there are only two crops (apples and grapes) that permit a concentration of extension services and good monitoring of pest control and crop management programs. Another is the Emilia-Romagna, which in the past 3 years has implemented an IPM project involving 170 extension service personnel and $\approx$ 3000 farms (1800 ha). The region also boasts a newly established biofactory for the rearing of beneficial insects that are now being employed in certain greenhouse crops and maize. Yet, this is only a fraction of the farms in the region, not to mention the country's other areas, where the picture is even less developed. Much work still needs to be accomplished before integrated farming becomes a truly nationwide reality and not simply the privileged preserve of a few pilot or commercial "cover" farms.

\section{Policy guidelines for integrated fruit growing}

No project can reasonably be expected to achieve its goals unless it is firmly grounded initially in a broadly based comprehensive training and education program in four areas:

1) Providing a nucleus of highly skilled technical personnel. The latter must be coordinated closely by a central management authority that is to act as the link among scientific institutions, research centers, and local experimental farms. Provisions also must be made to update training courses for these technicians, who are to be skilled by sector (e.g., IPM, nutrients-irrigation) and not by generalities. They must not be assigned impossible and, untenable tasks, but must operate within consortium groups, such as cooperatives and associations, that will monitor their work as well as being the voice ofthe needs and ideas of growers.

2) Professional training for growers. These activities under EEC inducement have been relegated to a myriad of professional training centers, clearly political in character and far too piecemeal in structure to carry out the tasks assigned to them successfully and without overlapping.

3) Incentives for pilot, experimental, and/ or extension service stations run by farm development agencies or by intermediary boards promoted by regional authorities and run by grower organizations. Growers must have ready access to educational and service agencies and be able to visit pilot farms periodically, where they can see farm operations first hand, recognize disease, and adapt innovations to their needs.

4) Promoting blanket and continuous consumer-education campaigns. This must be accomplished through the most influential mass media channels to explain options available to the public. In addition, the function should be to advertise certified produce and to counter vested economic interests that can be detrimental to a nation's agriculture.

\section{Services for integrated production}

Experience has shown that improvement and change through the adoption of the above principles is most readily effected by implementing low, rather than high, environmental-impact technology to correct current imbalances and curtail the use of chemicals, which are more costly, polluting, and/or incompatible with the objectives of modern integrated farming. Examples of low-environ- mental impact technologies are as follows:

1) Soil analysis laboratories. They should include consultations with growers as to soilcrop compatibility, fertilization requirements, leaf diagnostics, and analytical data interpretations.

2) Agricultural meteorology. This system should be linked to national weather networks to furnish growers with "real time" forecasting and information as well as guidelines for such practices as irrigation, management operations, hail protection, and area planning.

3) Crop mapping. This depends on proper coordination of soil analysis and meteorology and is designed to formulate "strategic surveys" for planning crop investments. It requires pomologists and olericulturists to periodically draw up cultivar recommendation lists and to establish market evaluation studies.

4) Nursery innovation. The aim is to promote advances for cultivar integrity and phytosanitary certification by establishing centers for virus-free material, in vitro laboratories for micropropagation, mycorrhization, and the addition of beneficial bacteria (bacterization) to seedlings and other propagules.

5) Promotion of IPM techniques and monitoring stations and alternative crop management practices.

6) Irrigation scheduling and planning that includes systems servicing, timetables, and supply modes as a function of soil and specific crop.

7) Crop quality control. This should encompass indications as to ripening and harvest dates as well as laboratories or similar facilities to monitor pesticide residues in crops. tion.

8) Postharvest and cold storage informa-

9) Accounting. Consultancy for growers to assist in cost-benefit analysis of the innovations and conversion plans related to integrated farming.

The implementation of these services should receive high priority in establishing integrated farming as a vital program and not merely an empty formula in legislative proposals. The resources of the private sector alone are insufficient to coordinate and manage them without cooperation of university and public research institutions. In Italy, regional authorities can commission and finance experimental interdisciplinary projects to be jointly managed by grower organizations, the members of which are the ultimate beneficiaries of any tangible results.

\section{Sectors receptive to low-environmental- impact technology advances}

The fruit industry is well-situated to exploit the latest innovation in low-environmental-impact technology. The following sectors are those in which this conversion can most readily be pursued without detriment to crop quality and yield,

New orchards. Deep plowing is unnecessary under appropriate soil conditions. Re- 
gional extension services can furnish information as to fertilizers, additional nutrients, and the organic matter most appropriate to improving soil structure and preserving adequate fertility.

Orchard fertilization. The use of chemical fertilizers has undergone extensive review because of widespread abuses in application. Recommendations include overall reductions in nutrients, including phosphorus and potassium, in soils already rich in these elements, and restricting the input of nitrogen to the amount removed by the crop.

Weed control. Chemical weed control can be completely eliminated in orchard and vineyard management with no appreciable differences, save the extra cost of interrow surface tilling. Satisfactory weed control can also be accomplished by mulching with plastic film, residual organic matter, or "seeded grass' swards, a practice increasingly common in orchards and vineyards. Here, controlled-growth grass is sown and then frequently cut to replenish organic matter (mainly as a source of $\mathrm{N}$ ) and to reduce competition with the crop. Chemical control can be restricted to only once or twice annually in the earliest years of orchard life. There are various alternate options that can be adopted to given local conditions.

Pest management. IPM techniques are to be resolutely pursued and implemented. Promoting the development of beneficial insect populations has generally contributed to reduced reliance on pesticides, although results in some cases have not wholly lived up to expectations. In certain years, however, the dynamics of biological and climatic factors have resulted in negative consequences for plants, fruit quality, and, surprisingly, even for residues. Toxic substances have occassionally been found in higher concentrations in fruit challenged by depredation than in those that have been properly. treated with conventional methods.

Irrigation. Localized application techniques, such as drip and sub-canopy sprinklers (microjet, spray), have increased irrigation in certain areas and lowered both capital outlays and overhead. Innovations in water- and energy-saving techniques based on temporary controlled water deficits require less water input than was normally deemed necessary. The effect is to reduce competition in critical periods between vegetative growth and fruiting, when new shoots are already well-developed.

Training of trees. Training and pruning systems in conjunction with the concept of self-regulating tree growth are extremely important. Training that emphasizes the reproductive or bearing over the vegetative stage from the very first years of orchard life reduces pruning costs and induces early cropping. Fruit thinning is also important to prevent excessive load, alternate bearing, irregular size, and precocious exhaustion of orchard life. These techniques are also designed to recycle the biomass of the entire orchard (leaves, grass, chopped pruning wood) to replenish the soil's organic matter and enhance soil structure.
Spraying. The most important innovations today are in sprayers. The design changes from high to low volumes and a radical improvement in spray distribution (e.g., air convection mode, horizontal or angled flow, and electrostatic charges), enable more-uniform coverage and reduction of concentration and drift loss. The percentage of active ingredients lost on the ground, with resultant pollution, can exceed $80 \%$ of the amount applied.

Harvest. Mechanization is to be planned and targeted so as to prevent energy waste, reduce soil compaction, and to eliminate sophisticated and costly harvesters that are little more than status symbols that cannot be justified in terms of overhead.

Postharvest and storage. Determining harvest dates to assure high fruit quality standards is of vital importance. It has usually been left up to commercial agents with an eye to market speculation. The practice is detrimental to the natural expression of the fruit's flavor qualities as the crop is often picked too early and, even when subjected to artificial ripening, alienates the unsuspecting consumer. In addition, postharvest treatments designed to extend storage life are all too frequent. Despite the most advanced controlled-atmosphere techniques, these methods increase residue levels over conventional storage and, at times, even exceed established limits. These practices should be eliminated; storage life should be restricted only to that time span that does not impair quality. It is better to promote the consumption of fresh fruit and coordinate to full advantage the complementary, staggered ripening dates of fruit in different geographic areas. It is a mistake to market both underripened or over-ripened fruit. Technical means exist to determine both harvest and marketing maturity, as do the methods for handling and storing mature fruit. They are based on the knowledge of cultivars and their ripening stages, on precooking and a consistent chain of cold storage, on the use of controlled atmosphere in storage and in transport, and on proper packing for sale in supermarkets.

\section{Yield and quality}

An issue occasionally raised in the debate on the excessive technology dependence of agriculture is the proposal to conserve soil resources by restricting yields and/or the technical means to produce them-intensive management, chemical fertilizers, irrigation. The problem is misleading when couched in these terms. Rather, the critical issue is the suitability of an area for a given crop. For example, limiting vineyards to hillside or restricting fertility restricts yields, but assures high quality.

In fertile lowlands, however, it is impossible to limit yields, as farmers are not willing to eschew the technical means at their disposal unless they are compelled to do so by having to meet a certain quality standard. Only if the idea of limiting crops is profitable will the grower begin to use reduced production inputs such as restricted fertilizer or water. Such limitations will only be effected if enhanced product quality translates into higher market prices and increased total returns.

Integrated farming will be called on to face the challenge of these restrictive measures, and pressure, for political and economic reasons, will be brought to bear in order to eliminate surplus fruit and wine. When that time comes, we must be prepared. Ideally, orchards and vineyards would be located in areas with fertile soil, requiring limited inputs of nitrogen and water, but ecologically adapted to yield naturally high-quality produce. Fruit crops are indubitably best suited to hillside (piedmont) and, in certain cases, even lower mountain areas, The same zones, however, pose higher pollution risks from chemicals (pesticides, nitrates, herbicides) that seep downhill to contaminate streams and reservoirs supplying water to the population at large.

\section{Gene pool renewal and retrieval of environmental stress- and pest-resistant germplasm}

There is renewed interest worldwide in genetics as a means of countering the consequences of crop over-specialization and cultivar simplification. While these trends have led to the selection and differentiation of cultivars that are the most productive, as well as being the most responsive to the demands of market pressures, they have led to other problems (e.g., susceptibility to diseases, environmental stresses, and quality defects) that are decisive for the renewal of agriculture. So, even before we rely on genetic engineering and the problematic introduction of cure-all genes from distant organisms, it is necessary to explore the natural genetic heritage and recover, through painstaking work, all that nature can return to us without expecting miracles from molecular biology. Let us first use what we now have.

The orchard industry has three sectors that already offer significant alternatives: apples, pears, and grapes. These concern old cultivars and newly bred cultivars and selections. The former are being reintroduced into the list of marketable cultivars (e.g., in Piedmont, Emilia-Romagna, and Sardinia) and, although they may be a bit unappealing in appearance, they are firm, disease-resistant, aromatic, and tasty, and have long shelf-life without refrigeration. The latter are resistant to pathogens and pests; e.g., the success of $\approx 30$ apple cultivars released as scab- and mildew-resistant, the result of 40 years of work. Some of these are very promising, such as 'Florins', and make it possible to eliminate 15 to 20 fungicide sprays yearly. Finally, some fruit species require few pesticides and may be considered ecological fruits. Species such as kiwifruit and persimmon possess these attributes.

\section{Conclusions}

Integrated agriculture will be the key issue 
in the European Economic Community's farm policy of the 1990s. An adversarial confrontation between "organic" and "integrated" management techniques is unnecessary. Growers must, above all, take into account the mass market for which they produce. Consumers who demand produce free from chemical residues are to be protected, and growers wishing to convert their operations and produce for the "organic" market should have their crops designated by a "trademark of origin" (not necessarily of quality), permitting them to sell at higher prices so as to offset lower yields per hectare and greater management outlays. The government should limit its role to monitoring the origin of such produce, thereby safeguarding consumer interests. Yet, it should also inspect the crops grown under the integrated system. It must be remembered that the organic method represents an elite market, whereas the integrated system supplies the mass market; hence, the greater responsibility for government monitoring and analysis in the latter. These services should be targeted more to the larger, mass consumer market rather than to the smaller, elitist group.
It is necessary to encourage growers for both sectors to organize their own monitoring services and regulatory bodies through their associations and cooperatives. Given the enormous importance of these strategies in the agriculture and food industries, the information disseminated to both growers and consumers must be of high quality and timely. Here, again, the role of government is indispensable in reaching growers through extension service programs, in monitoring for compliance with standards and regulations, and in educating the public through the mass media.

Researchers must also bear responsibility in regard to the dissemination of well-documented information to growers and consumers alike. As the Nobel laureate Ilya Prigogine has put it: "We are heading toward a society in which personal responsibility will be greater than ever before" and we therefore must have "a greater awareness of nature and a greater solidarity among human beings" in the spirit of a "new alliance between man and the environment". This is the task and the challenge that tomorrow's agriculture will be called upon to meet.

\section{Literature Cited}

Baggiolini, M. and G. Fiaux. 1975. La lutte integrée dans les vergers suisses. Les phases evolutives de son introduction clans la pratique. Compt. Rend. Symp. Lutte integrée envergers. OILB/SROP (Organization Intl. Lotte Biologique). p. 27-36.

Marcelle, R. 1988. La production integrée fruitiere en Suisse. Le Fruit Beige 424:318-323.

Reinken, G. 1988. Integrierter gärtnerischer Pflanzenbau-Notwendigkeit, Probleme, Folgen. Gartenbauwissenschaft 53(5):193-198.

Sansavini, S. 1987. Per una frutticoltura in armonia con l'ambiente. Frutticoltura 49(12):917.

Sansavini, S. and P. Rosati. 1986. Resistenza genetics delle piante da frutto alle avversita parassitarie. Frutticoltura 48(8):37-54.

Steiner, R. 1979. Geisteswissenschaftliche Grundlagen zum Gedeihen der Landwirtschaft. R. Steiner Verlag Dornach, Schweiz.

Van Tiemann, K.H. 1989. Irrtegrierter Obstanbau an der Niederelbe. O.V.R. (Obstbau Versuchs Ring) 44(4):85-92.

Wedler, A. and G. Overbeck. 1987. Erfahrungen aus biologisch:dynsrnischen Anbauversuchen und Qualitätsuntersuchungen in der Versuchsanstalt Auweiler. Untersuchungen von Inhaltsstoffen im Gemüse. Biologisch-dynamischer Land-und Gartenbau. Forschung und Beratung Reihe C, 44:291-303. Miinster-Hiltrup. 